\title{
Biodegradation of flax fiber reinforced poly lactic acid
}

\author{
R. Kumar ${ }^{*}$, M. K. Yakubu', R. D. Anandjiwala ${ }^{1,3}$ \\ ${ }^{1}$ CSIR Materials Science and Manufacturing, Port Elizabeth, South Africa \\ ${ }^{2}$ Department of Textile Science and Technology, Ahmadu Bello University, Zaria, Nigeria \\ ${ }^{3}$ Department of Textile Science, Faculty of Sciences, Nelson Mandela Metropolitan University, Port Elizabeth, \\ South Africa
}

Received 24 February 2010; accepted in revised form 30 April 2010

\begin{abstract}
Woven and nonwoven flax fiber reinforced poly lactic acid (PLA) biocomposites were prepared with amphiphilic additives as accelerator for biodegradation. The prepared composites were buried in farmland soil for biodegradability studies. Loss in weight of the biodegraded composite samples was determined at different time intervals. The surface morphology of the biodegraded composites was studied with scanning electron microscope (SEM). Results indicated that in presence of mandelic acid, the composites showed accelerated biodegradation with 20-25\% loss in weight after 50-60 days. On the other hand, in presence of dicumyl peroxide (as additive), biodegradation of the composites was relatively slow as confirmed by only $5-10 \%$ loss in weight even after $80-90$ days. This was further confirmed by surface morphology of the biodegraded composites. We have attempted to show that depending on the end uses, we can add different amphiphilic additives for delayed or accelerated biodegradability. This work gives us the idea of biodegradation of materials from natural fiber reinforced PLA composites when discarded carelessly in the environment instead of proper waste disposal site.
\end{abstract}

Keywords: biodegradable polymers, amphiphilic additives, scanning electron microscope

\section{Introduction}

Biocomposites are usually fabricated with biodegradable/nonbiodegradable polymers as matrix and natural fibres as reinforcement. A number of lignocellulosic fibres, such as jute, hemp, sisal, abaca etc. are used as reinforcement for biodegradable biocomposites because of their good mechanical properties and low specific mass [1-4]. Extensive research is carried out on plastics and composites from poly(lactic acid) (PLA), a synthetic aliphatic polyester which is biodegradable and synthesized from renewable agriculture products, with properties comparable to some fossil-oil-based polymers [2]. Generally, biodegradation studies are carried out in soil and/or compost, in particular, enhanced biodegradation of these materials may occur in the presence of compost, a complex biological environment, in which microbial diversity is relatively high and therefore an increased degradation potential for polymeric compounds may result [5-7]. The improper disposal and treatment of solid waste is one of the gravest environmental problems faced by most of the countries. With the increasing globalization and modernization, generation of waste for disposal is likely to increase still further. In near future, biocomposite products that will be discarded by the consumer after use will become biocomposite wastes and these products do break down naturally by the air, moisture, climate, or soil and disintegrate in the surrounding land. But as more and more biodegradable materials pile up, there is increased threat to the environment so dur- 
ing processing of the materials, additives can be included for enhancing the rate of biodegradability of the biocomposites depending upon the end-uses of the products. Importantly, in many parts of the world proper waste disposal facilities do not exist and the wastes are simply discarded in the surrounding areas. Ultimately, we have to depend on the nature for biodegradation of the materials. In view of this thought it is of interest to conduct the biodegradation studies of the biocomposites for natural fiber reinforced PLA in farmland soil in presence of amphiphilic additives and thereby assess the effectiveness of the various additives on the biodegradability of the material.

In this short communication we report the biodegradation studies conducted in the farmland soil for woven and nonwoven flax fibres reinforced PLA composites using amphiphilic additives. The physico-mechanical properties of these composites are discussed in detail in two of our recent papers under publication $[8,9]$. PLA used in this study contains cereal starch (wheat, potato and tapioca) for improved biodegradability. Biodegradation studies were based on the estimation of the loss in weight of the composites with time. Fourier transform infrared spectra (FTIR) and scanning electron microscopy (SEM) were used to assess the degradation of the material. The application areas of the biocomposites from PLA will expand further if the materials degrade faster after their end-uses. The objective of this work is to investigate the rate of biodegradation of flax/PLA biocomposites in the presence of different additives. An attempt is made to ascertain the extent of acceleration that can be achieved.

\section{Experimental}

\subsection{Materials}

PLA resin (CP-INJ-1001EZC) was obtained from Cereplast, Inc, Hawthorne, USA (MFI@ 190 as determined by D1238 method is $10-12 \mathrm{~g} / \mathrm{min}$, HDT is $44.4^{\circ} \mathrm{C}$ at $4.6 \mathrm{MPa}$ (66 psi)). To improve the biodegradability of the PLA resin, supplier has incorporated cereal starch (wheat, potato and tapioca) in this grade of resin. Flax nonwoven web of $110 \pm 20 \mathrm{~g} / \mathrm{m}^{2}$ was prepared by needle punching technique on a pilot plant at CSIR, Port Elizabeth, South Africa. Flax woven fabric of $180 \pm 10 \mathrm{~g} / \mathrm{m}^{2}$ was purchased from Libeco, Belgium with
$19 \mathrm{warp} / \mathrm{cm}$ and $21 \mathrm{weft} / \mathrm{cm}$. Benzilic acid, mandelic acid and dicumyl peroxide (DCP) were procured from Sigma-Aldrich, Germany. Zein protein was obtained from Scientific Polymer Products, New York, USA and chloroform was purchased from Minema Chemicals, South Africa. All laboratory grade chemicals were used without further purification.

\subsection{Preparation of the composites}

In a typical process, a square nonwoven or woven web of $15 \mathrm{~cm} \times 15 \mathrm{~cm}$ in dimensions with an average mass of $2.5 \mathrm{~g}$ (for nonwoven) or $4 \mathrm{~g}$ (for woven) was cut and dried in an oven at $60^{\circ} \mathrm{C}$ for $24 \mathrm{~h}$ to remove moisture. PLA pellets equivalent to 0.8 and 0.7 weight fractions of the nonwoven web and woven fabric, respectively were dissolved in chloroform. It is to be noted that nonwoven flax fiber requires higher amount of PLA than woven ones. The dried nonwoven web/woven fabric was then placed inside a square metal frame mold of $15 \mathrm{~cm} \times 15 \mathrm{~cm}$ in dimensions and the PLA solution was poured over the nonwoven web or woven fabric. It was observed that 5 to $6 \mathrm{~g}$ of PLA in $100 \mathrm{ml}$ chloroform gave homogeneous solution for wetting the fibres in the nonwoven web or woven fabric. We are using chloroform to dissolve PLA in the initial stage of our research although we are aware of the fact that chloroform is not suitable for the environment. Once we get the idea of suitable additives for accelerated degradation we will prepare the samples by injection molding without using the solvent. The assembly was kept at a room temperature for $24 \mathrm{~h}$ to evaporate the solvent. The solution-cast samples with one layer of nonwoven web/woven fabric were subsequently hot pressed at $190^{\circ} \mathrm{C}$ under 50 bar pressure for $15 \mathrm{~min}$ to get the composite samples. The solution-cast composites followed by compression molding with different additives ( $1 \%$ w/w w.r.t PLA) were prepared at 0.2 and 0.3 weight fraction of the fibers $\left(W_{f}\right)$ of the nonwoven web and woven fabric, respectively by following the procedure described above. The composites, thus prepared from nonwoven web, were designated as PFB-NW, PFM-NW, PFD-NW, PFZ-NW where $\mathrm{B}, \mathrm{M}, \mathrm{Z}$, and $\mathrm{D}$ represent benzilic acid, mandelic acid, zein, and DCP, respectively. PF-NW represents the composites prepared without additives. Similarly, the composites prepared from 
woven web were designated as PFB-W, PFM-W, PFD-W, PFZ-W. PLA-fibre composite prepared without additive is designated as PF-W. PF represents flax fiber reinforced PLA composites while NW and W represent nonwoven and woven flax fabric, respectively. The thickness of the composites with one layer of nonwoven or woven fabric, prepared by compression molding at 50 bar pressure, was found to be $0.65 \pm 0.05 \mathrm{~mm}$. The composites thus prepared were free from voids and solvent as the samples obtained after solution casting were pressed (50 bar pressure) in compression molding machine at $190^{\circ} \mathrm{C}$ for $15 \mathrm{~min}$.

\subsection{Characterizations}

For biodegradability test, the composite sheets were cut into $40 \times 20 \mathrm{~mm}$ rectangular specimens. Biodegradability test was carried out in a flower pot containing farmland soil having $\mathrm{pH} 7.5-7.7$ by maintaining high relative humidity $(\sim 98 \%)$ by daily sprinkling water. Each specimen was buried in the soil kept in a flower pot (30 cm diameter) at room temperature $\left(25 \pm 5^{\circ} \mathrm{C}\right)$. Each specimen was dug out of the farmland soil after buried for 20, 30, 40, 50, $60,70,80$ and 90 days, respectively, and then washed with water and dried at $60^{\circ} \mathrm{C}$ in an air oven for $48 \mathrm{~h}$. Biodegradability was determined by measuring loss in weight of the specimens. To maintain uniformity in the results only one sample was tested at each condition.

Scanning electron microscopy (SEM) images of the surface of the biodegraded composites were taken on FEI Quanta 200 (Eindhoven, The Netherlands) electron microscope at an accelerating voltage of $10 \mathrm{kV}$ in low vacuum. Differential scanning calorimetry (DSC) of the composites was carried out on a Diamond DSC (Perkin Elmer) in the temperature range of 25 to $220^{\circ} \mathrm{C}$. Fourier transform infrared spectra (FTIR) of the composites before and after degradation were carried out on a Spectrum 100 FT-IR (Perkin Elmer USA) in the range from 4000 to $600 \mathrm{~cm}^{-1}$ using composite powders.

\section{Results and discussion}

Films prepared from neat PLA degraded rapidly compared to natural fiber reinforced composites. About $4.2 \%$ weight loss was observed in neat PLA after 20 days of burial in soil degradation test. After
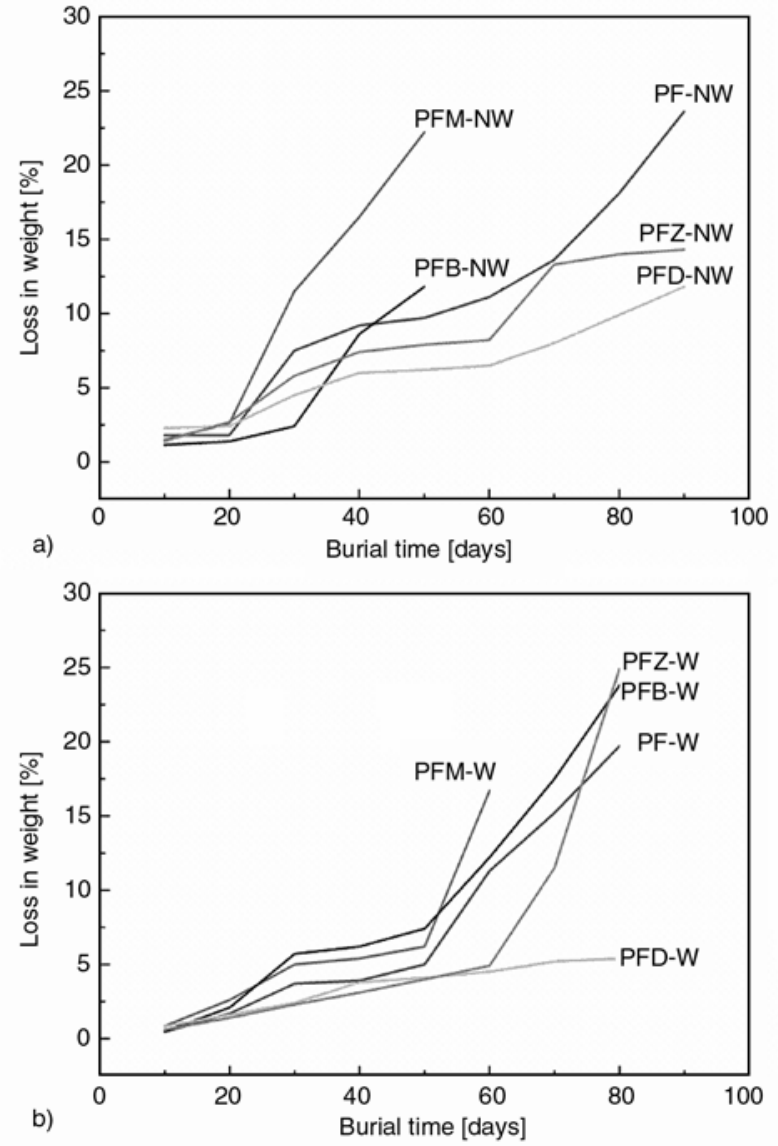

Figure 1. Loss in weight of the buried composite samples in farmland soil with different additives. In the above figures, PF represents flax fiber reinforced PLA composites while NW and W represent nonwoven and woven flax fabric, respectively. $\mathrm{M}, \mathrm{B}, \mathrm{Z}$ and $\mathrm{D}$ represent mandelic acic, benzilic acid, zein protein and dicumyl peroxide, respectively that has been added to the composites during preparation.

20 days, neat PLA samples were brittle so further study on PLA film was discontinued. Figure 1 shows the loss in weight of the biodegraded flax fiber reinforced composites over the soil burial degradation period of 90 days. After 90 days, composite samples partially disintegrated so further studies on the biodegradation of the composites in soil was discontinued. Lag phase/time of about 20 days was observed in the biodegradation curves. Woven and nonwoven reinforced composites showed $5-25 \%$ of weight loss after the designated lag time. The loss in weight increased with the increase in burial time for all the specimens. The presence of DCP delayed the rate of biodegradation of the composites in soil with resultant loss in weight of $11.4 \%$ (after 90 days) and 5.5\% (after 80 days) for PFD-NW and PFD-W, respectively. 


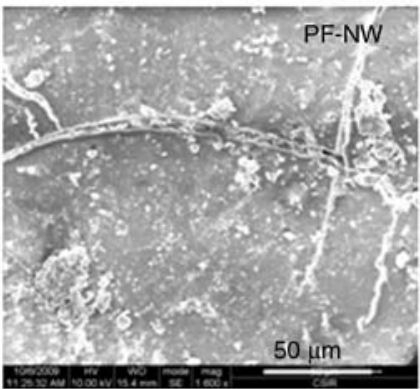

90 days

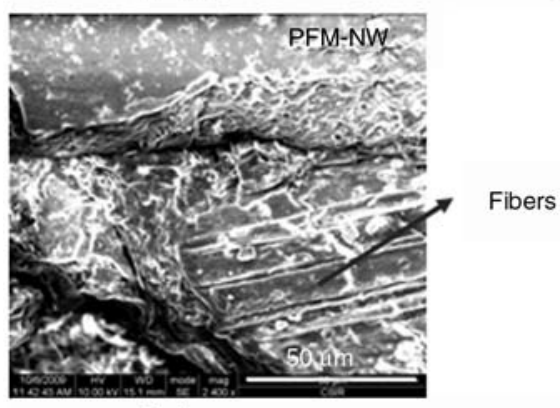

a)

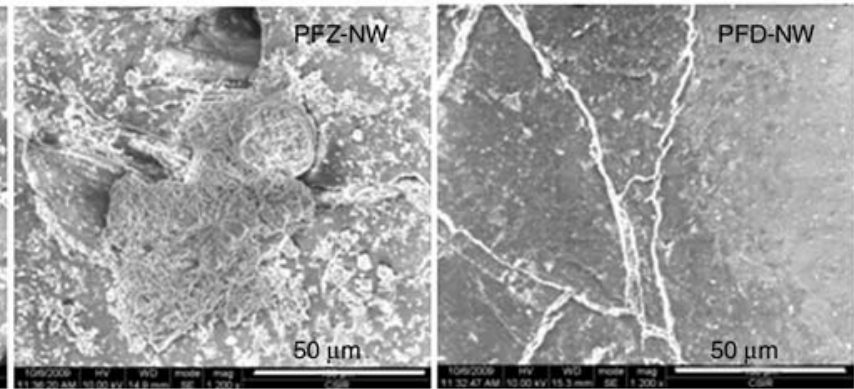

90 days
90 days

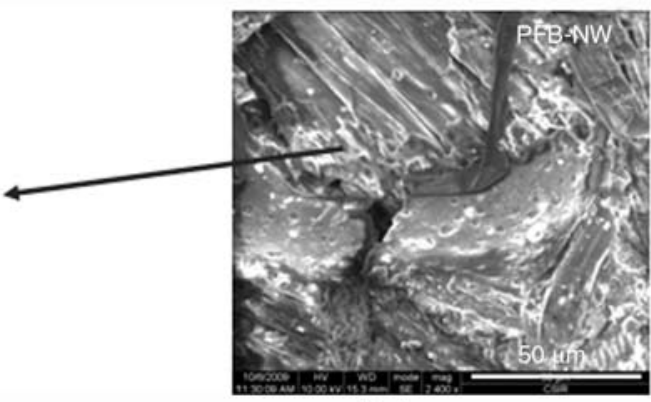

50 days

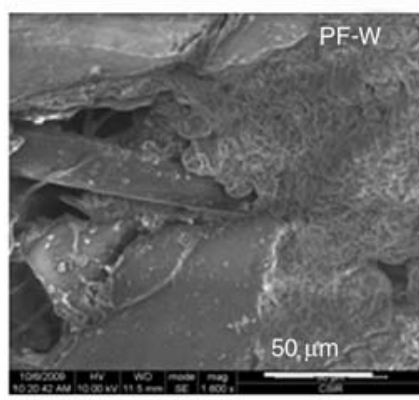

80 days

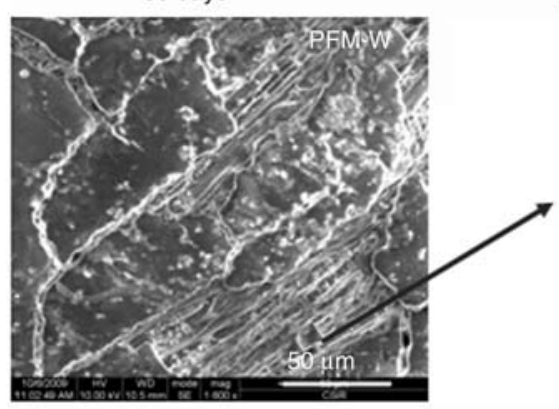

b)

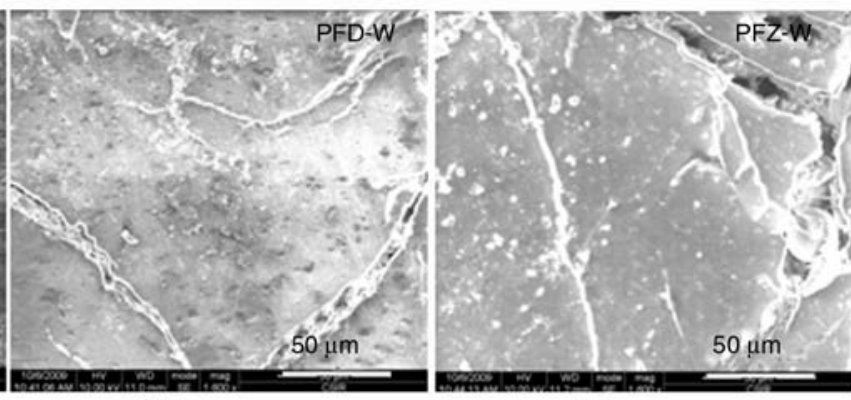

80 days

Fibers

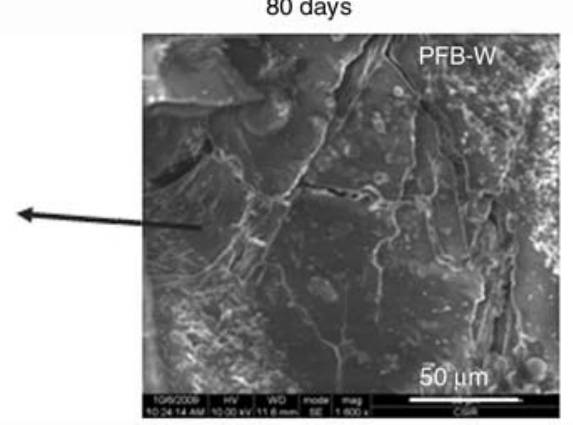

80 days

Figure 2. Surface morphology of nowoven reinforced PLA composites in presence of different additives. Cracks in the PFD-NW are observed indicating stability of composites. Fibers are observed on the surface of the PFM-NW, PFB-NW (a) and PFM-W, PFB-W (b) composites after biodegradation indicating accelerated degradation in presence of that particular additive.

On the other hand, the presence of mandelic acid accelerated the rate of degradation of the composites in the soil with resultant loss in weight of $22 \%$ (after 50 days) and $16.7 \%$ (after 60 days) for PFMNW and PFM-W, respectively. Higher rate of degradation of the composites in presence of mandelic acid may be due to the removal of PLA from the surface upon biodegradation as confirmed by Figure 2 [10]. Additionally, in presence of benzilic acid composites also showed accelerated biodegradation in soil. The percentage loss in weight after biodegradation in nonwoven composites is higher than woven ones. This is due to the fact that in case of nonwoven reinforced composites, due to higher 
amount of PLA, the microorganisms in soil can degrade the composites more effectively. Thus in addition to hydrolysis in PLA biological degradation has also taken place in the composites.

Figures $2 \mathrm{a}$ and $2 \mathrm{~b}$ show the surface morphology of the composites degraded in the soil. After 80 and 90 days, the cracks on the surface of the PF-NW, PF-W, PFD-NW, PFD-W, PFZ-NW and PFZ-W composites are apparent. Additionally, one or two fibers are also seen in PF-W and PFZ-W. The pres-
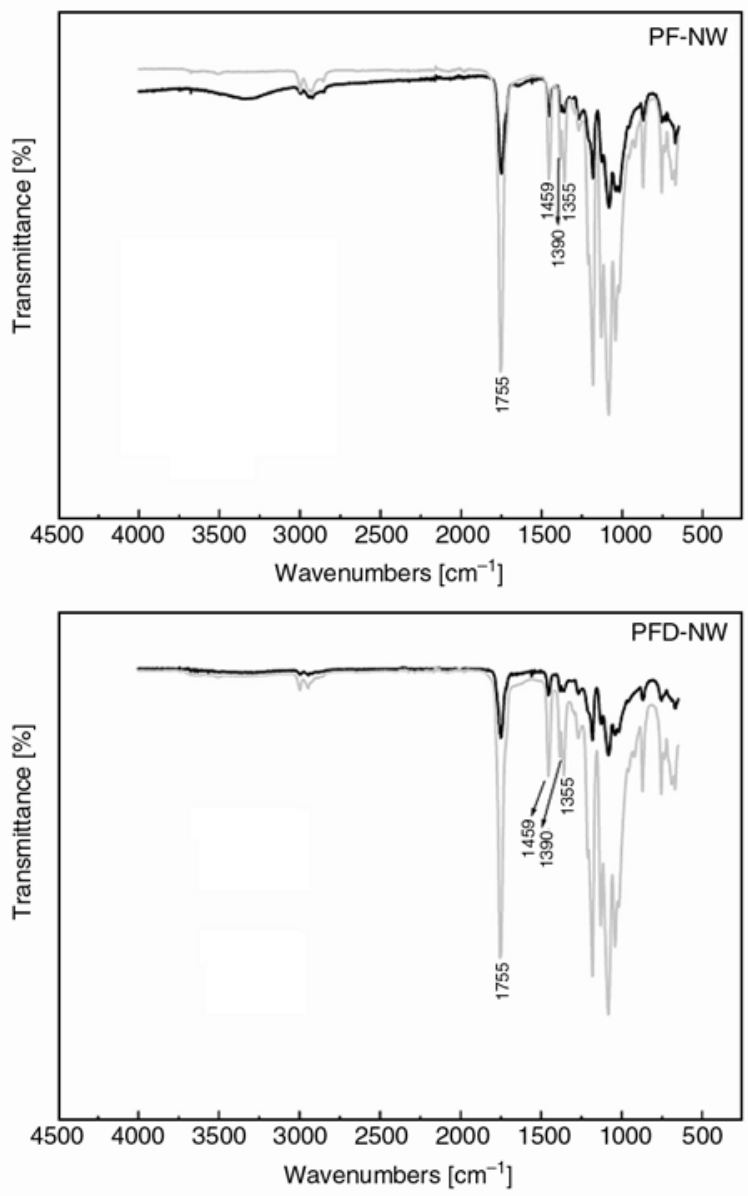

Table 1. Percentage crystallinity $\left(\% \chi_{c}\right)$ of woven and nonwoven fiber reinforced PLA composites determined by DSC thermal scans

\begin{tabular}{|l|c|l|c|}
\hline \multicolumn{2}{|c|}{$\begin{array}{c}\text { Nonwoven fiber reinforced } \\
\text { PLA composites }\end{array}$} & \multicolumn{2}{c|}{$\begin{array}{r}\text { Woven fiber reinforced } \\
\text { PLA composites }\end{array}$} \\
\hline \multicolumn{1}{|c|}{ Sample } & $\boldsymbol{\%}_{\mathbf{c}}$ & Sample & $\boldsymbol{\%}_{\mathbf{c}}$ \\
\hline PLA & 11.0 & PLA & 11.0 \\
\hline PF-NW & 8.0 & PF-W & 5.8 \\
\hline PFB-NW & 9.4 & PFB-W & 6.8 \\
\hline PFD-NW & 5.4 & PFD-W & 7.0 \\
\hline PFM-NW & 10.3 & PFM-W & 7.1 \\
\hline PFZ-NW & 9.3 & PFZ-W & 6.6 \\
\hline
\end{tabular}
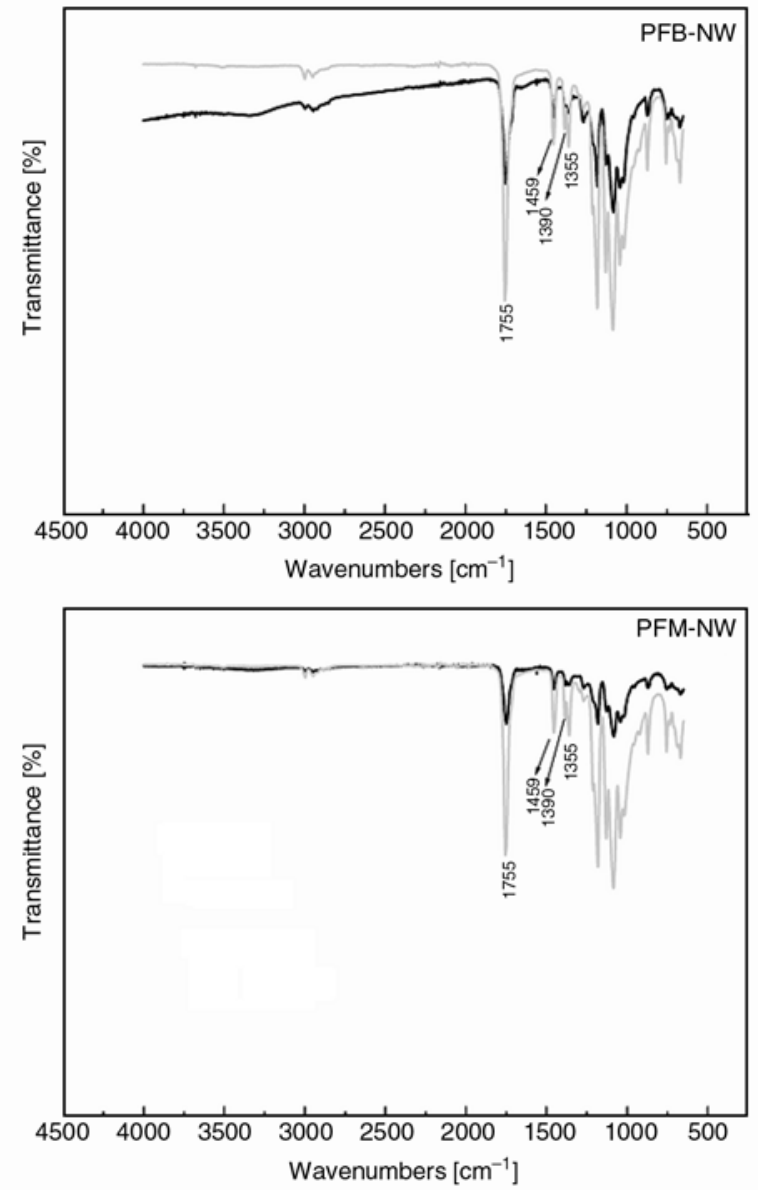

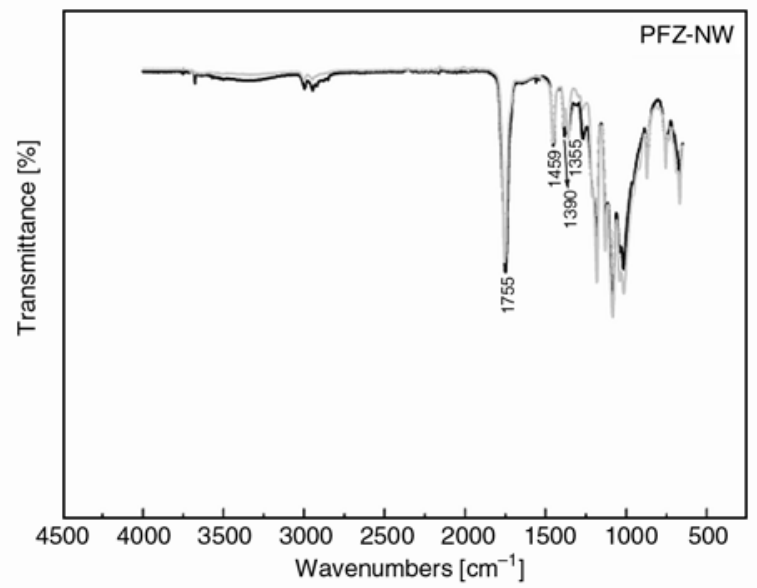

Figure 3. FTIR spectra of nonwoven fiber reinforced PLA composites in presence of different additives. In the FTIR spectra black line represents composite samples before degradation and grey line represents after degradation. 
ence of cracks in PFD-NW and PFD-W samples showed the stability of the composites towards degradation in soil and is well confirmed from the low percentage loss in weight even after 90 days. In the case of biodegraded PFM-NW, PFB-NW, PFM-W and PFB-W composites, the fibers are being observed on surface as evidenced from SEM study indicating removal of PLA from the surface of the composites in presence of mandelic acid. This directly refers to the accelerated degradation
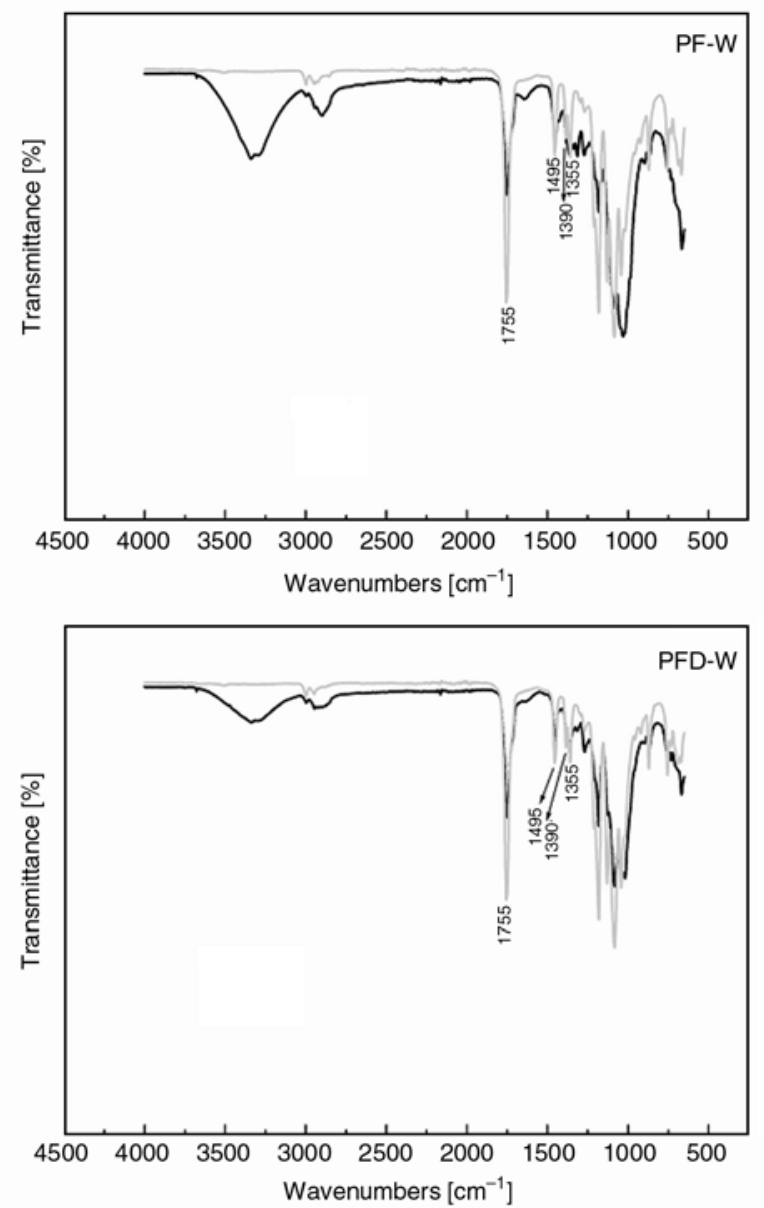

of the composites in the presence of mandelic and benzilic acids and is well confirmed by the high percentage loss in weight for PFM-NW/PFM-W or PFB-NW/PFB-W after degradation (Figure 1). To ascertain the reason for high or low stability of composites towards degradation we have estimated gel content of the composites before degradation. The gel content of the composites was determined according to ASTM D 2765. Each sample of about $0.2 \mathrm{~g}$ was oven dried at $70^{\circ} \mathrm{C}$ for $24 \mathrm{~h}$ and then
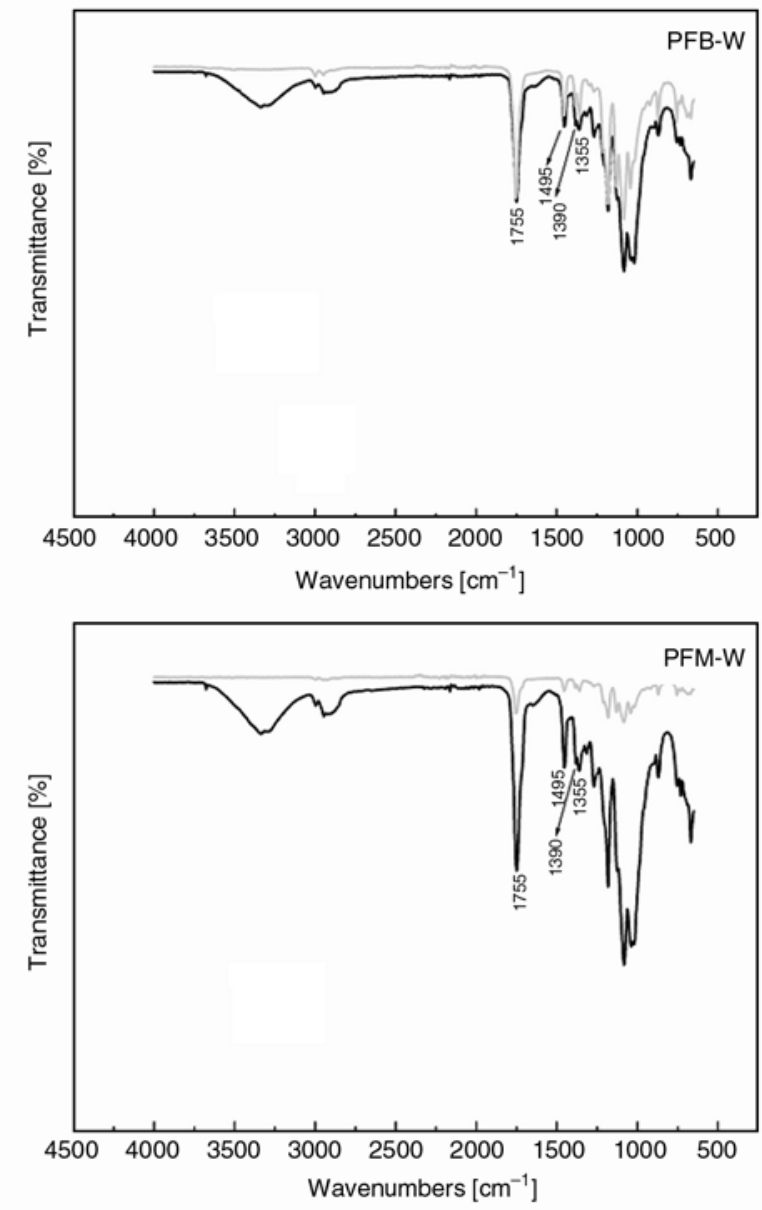

PFZ-W

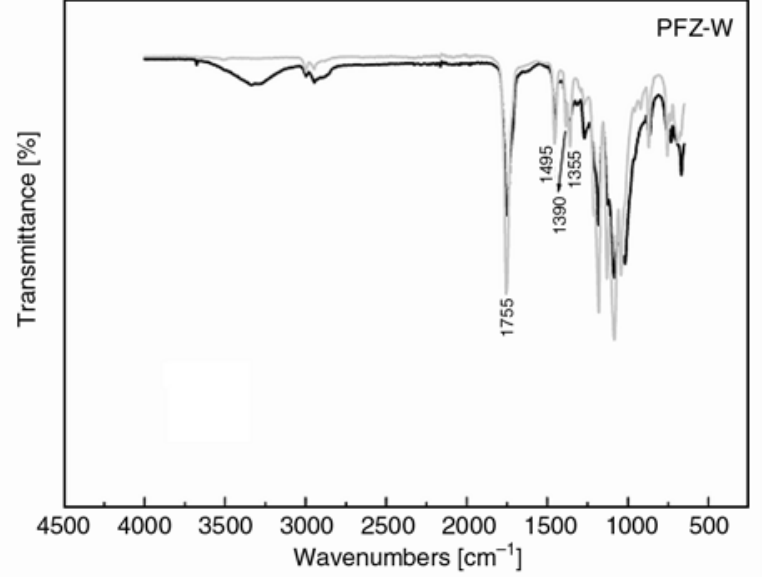

Figure 4. FTIR spectra of woven fiber reinforced PLA composites in presence of different additives. In the FTIR spectra black line represents composite samples before degradation and grey line represents after degradation. 
immersed in $20 \mathrm{ml}$ of chloroform for $24 \mathrm{~h}$ at a room temperature. The gel content was calculated as a fraction of residual PLA in the composite after subtracting the weight of the fibre. PFD-NW and PFD-W showed highest gel content $(\sim 12.3 \%)$ among all the composites, which indicates possible crosslinking in the presence of DCP attributable to free radical initiator nature of DCP.

The DSC results on percentage crystallinity $\left(\% \chi_{c}\right)$ of PLA based composites are shown in Table 1. The melting enthalpy of $100 \%$ crystalline PLA was taken as $135 \mathrm{~J} / \mathrm{g}$ [11]. There is an increase in $\% \chi_{c}$ for PFM-NW, which may have resulted from the presence of nucleating site from the amphiphilic additives. Both mandelic acid and benzilic acids are highly crystalline in nature. Presence of only one aromatic ring in mandelic acid provided more crystallising tendency in PLA in comparison to benzilic acid with two aromatic rings. The crystallization of PLA based composites tends to shift to higher temperature than PLA alone (not shown). Overall, the $\% \chi_{c}$ of the PLA decreased with the introduction of additives. $\% \chi_{c}$ of the PLA used in this study is much lower than that reported in the literature [12], and this is attributed to the fact that to improve the biodegradability of the PLA resin, supplier has incorporated cereal starch (wheat, potato and tapioca) in this grade of resin.

The influence of biological environment on the changes in chemical structure of the native and biodegraded composites can be investigated by the analysis of the infrared spectra. The FTIR spectra for woven and nonwoven reinforced composites were measured for samples before and after burial in soil and are presented in Figures 3 and 4. Degradation of composites is indicated mostly by increase of the band intensity corresponding to the $\mathrm{C}-\mathrm{H}$ deformational vibrations of $\mathrm{CH}_{3}$ groups present in polylactide segments $\left(1355,1390 \mathrm{~cm}^{-1}\right)$. The intensities of the $-\mathrm{C}=\mathrm{O}$ bands of PLA show sharpening and increase after biodegradation. The changes of $-\mathrm{C}=\mathrm{O}$ band are associated with the increase in the number of carboxylic end groups in the polymer chain during the hydrolytic degradation as well as in the cycle of microbial attack [13]. In the case of PFM-W (Figure 4) there is decrease in all the band intensities after biodegradation. FTIR spectra of PFM-W support the fact that there is removal of PLA from the surface upon biodegra- dation. In the case of PFM-NW (Figure 3) the PLA content is more and the fibers are well dispersed and that is the reason why the FTIR spectra of PFM-NW and PFM-W are not the same. However, surface morphology of both the degraded composites appears almost similar. The presence of degraded fibers with less PLA adhered in PFM-W and PFM-NW composites are also confirmed by the SEM micrographs (Figures 2a, 2b).

\section{Conclusions}

Biodegradability of flax fiber reinforced PLA based composites in presence of amphiphilic additives was investigated by soil burial test. Regarding the effect of amphiphilic additives on the biodegradability of composites, the higher loss in weight is obtained in the presence of mandelic acid. This is confirmed by the removal of PLA from the surface of the composites upon biodegradation as evidenced from the SEM study. In the presence of DCP, the biodegradability of the composites was comparatively delayed. Depending on the end-uses of the biocomposites, we can add suitable amphiphilic additives as triggers for inducing controlled biodegradation.

\section{Acknowledgements}

One of the authors, M. K. Yakubu is grateful to the Macarthur Foundation for providing the Post Doctoral Research Fellowship to work at CSIR MSM, Port Elizabeth, South Africa.

\section{References}

[1] Lee S-H., Wang S.: Biodegradable polymers/bamboo fiber biocomposite with bio-based coupling agent. Composites Part A: Applied Science and Manufacturing, 37, 80-91 (2006).

DOI: $10.1016 /$ j.compositesa.2005.04.015

[2] Oksman K., Skrifvars M., Selin J-F.: Natural fibres as reinforcement in polylactic acid (PLA) composites. Composites Science and Technology, 63, 1317-1324 (2003).

DOI: $\underline{10.1016 / \mathrm{S} 0266-3538(03) 00103-9}$

[3] Mohanty A. K., Mubarak A. K., Hinrichsen G.: Surface modification of jute and its influence on performance of biodegradable jute-fabric/Biopol composites. Composites Science and Technology, 60, 1115-1124 (2000).

DOI: $\underline{10.1016 / \mathrm{S} 0266-3538(00) 00012-9}$ 
[4] Sinha Ray S., Yamada K., Okamoto M., Ueda K.: Control of biodegradability of polylactide via nanocomposite technology. Macromolecular Materials and Engineering, 288, 203-208 (2003).

DOI: $10.1002 /$ mame. 200390013

[5] Itävaara M., Karjomaa S., Selin J-F.: Biodegradation of polylactide in aerobic and anaerobic thermophilic conditions. Chemosphere, 46, 879-885 (2002).

DOI: $10.1016 / \mathrm{S} 0045-6535(01) 00163-1$

[6] Shogren R. L., Doane W. M., Garlotta D., Lawton J. W., Willett J. L.: Biodegradation of starch/polylactic acid/poly(hydroxyester-ether) composite bars in soil. Polymer Degradation and Stability, 79, 405-411 (2003).

DOI: $10.1016 / \mathrm{S} 0141-3910(02) 00356-7$

[7] Martucci J. F., Ruseckaite R. A.: Biodegradation of three-layer laminate films based on gelatin under indoor soil conditions. Polymer Degradation and Stability, 94, 1307-1313 (2009).

DOI: $10.1016 /$ j.polymdegradstab.2009.03.018

[8] Kumar R., Yakubu M. K., Anandjiwala R. D.: Flax fibre reinforced poly lactic acid composites with amphiphilic additives. Plastic Rubber and Composites: Macromolecular Engineering, in press (2010).
[9] Kumar R., Yakubu M. K., Anandjiwala R. D.: Effect of montmorillonite clay on flax fabric reinforced poly lactic acid composites with amphiphilic additives. Composites Part A: Applied Science and Manufacturing, in press (2010)

[10] Fukuzaki H., Aiba Y., Yoshida M., Asano M., Kumakura M.: Synthesis of biodegradable poly(L-lactic acid-co-D,L-mandelic acid) with relatively low molecular weight. Die Makromolekulare Chemie, 190, 2407-2415 (1989).

DOI: $10.1002 /$ macp. 1989.021901007

[11] Miyata T., Masuko T.: Crystallization behaviour of poly(L-lactide). Polymer, 39, 5515-5521 (1998). DOI: 10.1016/S0032-3861(97)10203-8

[12] Yang S-L., Wu Z-H., Yang W., Yang M-B.: Thermal and mechanical properties of chemical crosslinked polylactide (PLA). Polymer Testing, 27, 957-963 (2008). DOI: 10.1016/j.polymertesting.2008.08.009

[13] Chlopek J., Morawska-Chochol A., Paluszkiewicz C., Jaworska J., Kasperczyk J., Dobrzyński P.: FTIR and NMR study of poly(lactide-co-glycolide) and hydroxyapatite implant degradation under in vivo conditions. Polymer Degradation and Stability, 94, 1479-1485 (2009).

DOI: $10.1016 /$ j.polymdegradstab.2009.05.010 